\title{
Production potential of cellulose nanofibrils from transgenic trees with reduced expression of cellulose synthase interacting 1
}

\section{Simon Jonasson}

Lulea University of Technology: Lulea Tekniska Universitet

Anne Bünder

Umeå Plant Science Centre: Umea Plant Science Centre

\section{Linn Berglund}

Luleå tekniska universitet: Lulea Tekniska Universitet

\section{Totte Niittylä}

Umeå Plant Science Centre: Umea Plant Science Centre

Kristiina Oksman ( $\nabla$ kristiina.oksman@ltu.se )

Luleå University of Technology https://orcid.org/0000-0003-4762-2854

\section{Research Article}

Keywords: Cellulose nanofibers, wood, fibrillation, network properties, transgenic trees

Posted Date: February 15th, 2022

DOI: https://doi.org/10.21203/rs.3.rs-1311812/v1

License: (9) This work is licensed under a Creative Commons Attribution 4.0 International License. Read Full License 


\section{Abstract}

Cellulose nanofibrils can be derived from the native load-bearing cellulose microfibrils in wood. These microfibrils are synthesized by a cellulose synthase enzyme complex residing in the plasma membrane of developing wood cells. In addition to the cellulose synthase complex several other proteins, including cellulose synthase interacting 1 (CSI1), facilitate cellulose biosynthesis. It was previously shown that transgenic hybrid aspen trees with reduced expression of CSI1 exhibit changes in wood mechanics and cellulose microfibril properties. We hypothesized that these changes in native cellulose may impact the quality of corresponding nanofibrils. To investigate this hypothesis wood from wild type and transgenic trees with reduced expression of CSI1 was subjected to oxidative nanofibril isolation processes. The transgenic wood extracted nanofibrils exhibited a significantly lower suspension viscosity and estimated surface area. Furthermore, the manufactured nanofibril networks exhibited a higher stiffness, reduced water-uptake, tensile strength, strain-to-break and degree of polymerization compared to wild type derived nanofibrils. It was concluded that the difference in wood properties caused by decreased expression of CSI1 gave rise to nanofibrils with distinctive qualities. The observed changes in the physicochemical properties suggest that the differences are caused by changes in apparent nanofibril aspect ratio and surface accessibility. This study demonstrates the possibility to influence wood derived nanofibril quality through genetic engineering of trees and opens for breeding of wood properties for extraction of nanomaterials with defined characteristics.

\section{Introduction}

Wood is a complex biological structure providing trees with the mechanical support needed to ensure upright growth whilst simultaneously facilitating the transport of nutrients and water (Groover et al., 2010). An important role of mechanical reinforcement in wood is performed by cellulose microfibrils (CMFs) which are hierarchical structures of $\beta(1 \rightarrow 4)$ linked D-glucose units which form glucan chains of nanoscale semi-crystalline fibrils in a bottom-up fashion (Fernandes et al., 2011). The CMFs are positioned throughout the wood cell walls where they are embedded in a hydrated matrix comprising primarily of hemicellulose and lignin (Knox, 2008). The resulting natural nanocomposite structure gives rise to the distinct properties of wood (Gibson, 1992).

The prospect of extracting CMFs as a value-added product from wood has gained attention over the past two decades. CMFs that have been subjected to isolation and purification processes are referred to as cellulose nanofibrils (CNFs) and inherit many of the distinct properties of CMFs, including high tensile strength (Wu et al., 2014), stiffness (Iwamoto et al., 2009), aspect ratio (Varanasi et al., 2013) and low coefficient of thermal expansion (Fukuzumi et al., 2009).

Development of various processing techniques have further enabled successful isolation of CNFs that closely resembles the most basic crystalline structures of the CMFs (Saito and Isogai, 2004; Saito et al., 2009; Wågberg et al., 2008). Through careful processing it is also possible to retain high degree of polymerization (DP) of the cellulose (Saito et al., 2009), which is manifested as longer CNFs (Henriksson 
et al., 2008; Shinoda et al., 2012). These process developments have further led to the prospect where the characteristics of CMFs are potentially influencing the isolated CNFs. Thus, understanding of how to alter CMFs in the original feedstock opens for the possibility to control final CNF characteristics.

The understanding of how CMFs are synthesized in plants has been described as one of the main challenges in plant biology (Saxena and Brown Jr, 2005). Research of the CMF synthesis machinery has revealed multiple proteins that are involved in this process (Polko and Kieber, 2019). One of the cellulose biosynthesis associated proteins that plays a crucial role in the alignment of the nascent CMFs into the cell wall is the cellulose synthase interactive 1 (CSI1) protein (Gu et al., 2010; Li et al., 2012). The plasma membrane localized cellulose synthase complex (CSC) moves in the plasma membrane during cellulose biosynthesis (Paredez et al., 2006). CSI1 guides the CSC along the cortical microtubules (cMTs) to align CMFs during primary cell wall biosynthesis (Bringmann et al., 2012; Li et al., 2012), and during the initial phase of secondary cell wall formation (Schneider et al., 2017). From a study of transgenic trees with reduced expression of $C S / 1$ it was observed that both stiffness and strength of the wood was decreased, as well as the cellulose DP (Bünder et al., 2020). There were no apparent structural or compositional changes in the wood cell wall of the transgenic lines which led to the hypothesis that a reduction of CSI1 may impact the mechanical properties of the wood by a reduction of the cellulose DP and thus altered CMF characteristics. It is thus of interest to isolate CNFs from these transgenic trees with a reduced level of CSI1 and assess the possible influence of the genetic modification on CNF properties.

To compare CNFs isolated from wild type (WT) and transgenic wood, mild ( $\mathrm{pH}=6.8$ ) direct oxidation using the catalytic system 2,2,6,6-tetramethylpiperidin-1-yl) oxyl (TEMPO) was employed together with high-pressure homogenization (Saito et al., 2009). This process has the benefit of allowing for direct oxidation of lignin and cellulose in one experimental step whilst preserving the cellulose DP (Jonasson et al., 2020; Kaffashsaie et al., 2021; Ma et al., 2012; Puangsin et al., 2017; Saito et al., 2009). Two transgenic lines with reduced expression of CS/1 were studied together with the control tree (WT) with normal CS/1 expression. The isolated CNFs were characterized in the dispersion state using viscosity, conductimetric titration, atomic force microscopy, yield- and surface area estimations. Networks were then manufactured from the dispersions and tested for DP, water-uptake and mechanical behavior. The characteristics of the CNFs and their networks are discussed in the context of initial wood properties.

\section{Materials And Methods}

\section{Materials}

Wood from hybrid aspen trees (Populus tremula $x$ tremuloides) was used as feedstock for CNF isolation. Two transgenic lines (T1+T2) with a significantly reduced expression of CS/1 and wild type trees (WT) were used in this study. The details of the genetic modification and characterization of these trees are described elsewhere (Bünder et al., 2020). The chemical and physical wood characteristics of the transgenic trees as measured by Bünder et al. (2020) are summarized in Table 1. (Bünder et al., 2020). 
According to the previous study the transgenic trees exhibit no significant differences in wood chemical composition, cellulose microfibril angle, wood anatomy and cell wall ultrastructure compared to WT.

Table 1

Physical and chemical wood characteristics of the trees that were used as feedstock in this study. Values in bracket correspond to standard deviation. Wild type (WT) and transgenic lines with reduced CSI1 expression (T1 and T2). Mean values that do not share letters are significantly different according to Tukey's test $(\mathrm{p}<0.05)$.

\begin{tabular}{|lllllll|}
\hline $\begin{array}{l}\text { Tree } \\
\text { ID }\end{array}$ & $\begin{array}{l}\text { Lignin content } \\
(\%)\end{array}$ & $\begin{array}{l}\text { Cellulose } \\
\text { DPn }\end{array}$ & $\begin{array}{l}\text { Modulus } \\
(\mathrm{GPa})\end{array}$ & $\begin{array}{l}\text { Strength } \\
(\mathrm{MPa})\end{array}$ & $\begin{array}{l}\text { Density } \\
\left(\mathbf{g ~ c m}^{-3}\right)\end{array}$ & $\begin{array}{l}\text { Stem diameter } \\
(\mathbf{m m})\end{array}$ \\
\hline WT & $21.5(0.8)^{\mathrm{a}}$ & $\begin{array}{l}1802 \\
(214)^{\mathrm{a}}\end{array}$ & $2.9(0.6)^{\mathrm{a}}$ & $33(3.6)^{\mathrm{a}}$ & $\begin{array}{l}0.35 \\
(0.02)^{\mathrm{a}}\end{array}$ & $6.8(0.9)^{\mathrm{a}}$ \\
\hline T1 & $20.2(0.5)^{\mathrm{a}}$ & $\begin{array}{l}1644 \\
(137)^{\mathrm{b}}\end{array}$ & $2.0(0.3)^{\mathrm{b}}$ & $27(6.0)^{\mathrm{ab}}$ & $\begin{array}{l}0.21 \\
(0.02)^{\mathrm{a}}\end{array}$ & $6.3(0.8)^{\mathrm{ab}}$ \\
\hline T2 & $20.5(1.1)^{\mathrm{a}}$ & $\begin{array}{l}1637 \\
(129)^{\mathrm{b}}\end{array}$ & $1.9(0.3)^{\mathrm{b}}$ & $22(4.8)^{\mathrm{b}}$ & $\begin{array}{l}0.32 \\
(0.04)^{\mathrm{a}}\end{array}$ & $6(1.1)^{\mathrm{b}}$ \\
\hline
\end{tabular}

Sodium chlorite (77.5-82.5\%, High-purity), standard hydrochloric acid ( $0.5 \mathrm{~N})$, standard sodium hydroxide solution $(0.1 \mathrm{~N})$, sodium hydroxide beads $(>97 \%, A C S)$ were purchased from VWR, Solna, Sweden. TEMPO (99\%), sodium hypochlorite ( $\mathrm{NaClO}, 6-14 \%$ active chlorine), Congo red and $1 \mathrm{M}$ copper (II) ethylenediamine solution were purchased from Sigma-Aldrich, Stockholm, Sweden AB. All chemicals were used as received.

\section{Methods}

\section{Wood oxidation and fibrillation}

The wood samples were ground and sieved through a $300-500 \mu \mathrm{m}$ mesh in to obtain powders with uniform particle size. The wood powder ( $2 \mathrm{~g}$ per sample) was dried in oven over night and then soaked in distilled water for 24 hours prior to starting the oxidation. Sodium chlorite (5.0 g/g wood) was added together with TEMPO to the vessel $(250 \mathrm{ml})$ containing the soaked wood powder and a phosphate buffer $(\mathrm{pH}=6.8$,$) . The vessels were submerged in a shaking water bath (Cole-Parmer Stuart, Staffordshire, UK)$ at $60^{\circ} \mathrm{C}$ for $1 \mathrm{~h}$ to dissolve the reagents. Reaction was started by adding sodium hypochlorite $(2 \mathrm{ml} / \mathrm{g}$ wood) and then resubmerged into the shaking bath for 48 hours. This procedure is an adaptation of the methodology described elsewhere (Saito et al., 2009) with modifications to the amount of reagent used and cellulose being in its native wood context instead of in wood pulp.

The final delignified and relatively swollen wood fibers were washed to remove reagent residues, dissolved lignin and hemicellulose. This was monitored by reaching a constant conductivity of the washing water. The oxidized samples were then adjusted to identical concentrations of $0.2 \mathrm{wt} \%$. 
The suspensions were then homogenized one pass without recirculation using an APV-2000 highpressure homogenizer (SPX Flow Inc, Silkesborg, Denmark) with an average flow rate of $4 \mathrm{~mL} / \mathrm{s}$ at a pressure of 1000 bar. The suspensions were accurately standardized with respect to solid content after homogenization prior to further characterization.

\section{Viscosity measurement}

The viscosity of the oxidized and homogenized suspensions was measured at various concentrations using a Vibro Viscometer (SV-10, A\&D Company Limited, Tokyo, Japan) with a tuning fork vibration method at a vibrational frequency of $30 \mathrm{~Hz}$. Concentrated suspensions $(0.30 \mathrm{wt} \%)$ were analyzed after dilution was performed for respective sample in $0.03 \mathrm{wt} \%$ increments down to $0.12 \mathrm{wt} \%$.

\section{Carboxylate content}

Carboxylate content was analyzed through the electric conductivity titration method adapted from (Saito and Isogai, 2004). $150 \mathrm{~mL}$ of respective CNF suspensions $(\approx 0.2 \mathrm{wt} \%)$ were protonated through addition of $0.1 \mathrm{M}$ hydrochloric acid and $0.01 \mathrm{M}$ sodium chloride. The suspensions were titrated with fresh $0.01 \mathrm{M}$ sodium hydroxide through $0.5 \mathrm{~mL}$ increments until pH 10 was reached. The amount of carboxylate groups $\left(\mathrm{mmol} \cdot \mathrm{g}^{-1}\right)$ induced from TEMPO-oxidation was calculated through Equation (1) below where $\mathrm{c}$ is the concentration of the sodium hydroxide, $V_{2}$ and $V_{1}$ is the volume of added sodium hydroxide at the end and start, respectively, $m$ is the mass of the cellulosic material in the sample, calculated through subtraction of added acid, base and salt mass from the oven dried suspension. The measurements were repeated three times and presented as mean.

$$
\text { Carboxylategroups }\left(\frac{m m o l}{g}\right)=\frac{C\left(V_{2}-V_{1}\right)}{m}
$$

1

\section{Atomic force microscopy}

Tapping-mode atomic force microscopy (AFM) Veeco MultiMode scanning probe microscope, (Santa Barbara, CA, USA) was used to confirm the presence of nanofibrils and analyze the morphology. Antimony-doped silicon cantilevers (TESPA-V2, Bruker, Camarillo, California) with a spring constant of 42 $\mathrm{Nm}^{-1}$ and a nominal tip radius of $8 \mathrm{~nm}$ were used for the analysis. Samples were prepared by depositing a small droplet of the CNF suspension $(0.001 \mathrm{wt} \%)$ on a freshly cleaved mica plate and letting it air dry for $\geq 5 \mathrm{~h}$. Around 100 fully individualized nanofibrils, total from four micrographs were analyzed for each sample and presented as a mean with corresponding standard deviation.

\section{Nanofibril and process yield}

Process yield was calculated as the washed gravimetric yield after the chemical treatment relative dry wood mass. The fraction of the process yield that comprised individual, colloidally stable nanofibrils were further quantified through centrifugation of the suspensions at $12000 \mathrm{xg}$ (Beckman Coulter J25i, 
Beckman Coulter AB, Bromma, Sweden) for 20 min at an approximate consistency of $0.2 \mathrm{wt} \%$. The suspensions were decanted, and the solids retained in the sediment were dried for $24 \mathrm{~h}$ at $95^{\circ} \mathrm{C}$. This was repeated three times and the nanofibril fraction was then calculated according to Equation (2) where $\mathrm{m}_{\mathrm{p}}$ and $m_{s}$ is the dry precipitate and supernatant mass in sample, respectively. The nanofibril fraction ( $\mathbb{E} \backslash \mathrm{P}$ ) was presented as fraction of the process yield.

$$
\Phi=1-\frac{m_{p}}{m_{p}+m_{s}}
$$

\section{2}

\section{Nanofibril surface area estimation}

Surface area of the nanofibrils were estimated in the never dried state by analyzing Congo red adsorption of the cellulosic fibers as described by (Spence et al., 2010). Briefly, the absorbed dye was quantified using a UV-vis spectrophotometer (GENESYS, 10 UV, Thermo Scientific, Schwerte, Germany) at the absorption maxima $500 \mathrm{~nm}$ and then translated to surface area (SSA) using Equation (3) and (4) where $\mathrm{E}$ is the solution concentration of Congo red at equilibrium $(\mathrm{mg} / \mathrm{ml}), A_{\max }$ is the absorbed amount of Congo red on the sample $(\mathrm{mg} / \mathrm{g}), \mathrm{K}_{\mathrm{ad}}$ is the equilibrium constant, $\mathrm{N}$ is Avogadros constant, $\mathrm{SA}$ is the theoretical surface area of a Congo red molecule $\left(1.73 \mathrm{~nm}^{2}\right)$ and $\mathrm{MW}$ is the molecular weight of Congo red (697 $\mathrm{g} / \mathrm{mole})$.

$$
\frac{\mathrm{E}}{\mathrm{A}}=\frac{1}{\mathrm{~K}_{\mathrm{ad}} \mathrm{A}_{\max }}+\frac{\mathrm{E}}{\mathrm{A}_{\max }}
$$

3

$$
\mathrm{SSA}=\frac{\mathrm{A}_{\max } \times \mathrm{N} \times \mathrm{SA}}{\mathrm{MW} \times 10^{21}}
$$

4

\section{Network manufacturing and characterization}

CNF suspensions were degassed for $30 \mathrm{~min}$ in a vacuum oven prior to vacuum filtration on hardened filter paper (Whatman, Grade 52, GE Healthcare, Machelen, Belgium, Pore size: $7 \mu \mathrm{m}$ ). The wet networks were carefully peeled from the filter paper and dried to around $14 \%$ solid content and characterized for water-uptake or further pressed $\left(2 \mathrm{kNm}^{-2}\right)$ for $10 \mathrm{~h}$. The dry networks were lastly compression molded using Fontijne Grotnes LPC-300 (Vlaardingen, Netherlands) between two mylar films (Lohmann Technologies, Knowl Hill, UK) at a pressure of $0.32 \mathrm{MPa}$ and at a temperature of $120^{\circ} \mathrm{C}$.

\section{Water uptake}


The wet networks were fully swelled in distilled water for $24 \mathrm{~h}$ prior to air drying in room temperature where after water-uptake was studied as a function of time when going from an air-dried state to fully hydrated. $0.1 \mathrm{~g}$ sections of the hydrogel were used and gravimetrically monitored over time.

\section{Mechanical testing}

The dry networks were cut into rectangular samples $(40 \mathrm{~mm} \times 5 \mathrm{~mm})$ using a mechanical punch. The samples were then stored at $50 \% \mathrm{RH}$ for at least two days prior to mechanical characterization.

Mechanical testing was performed using a Shimadzu AG-X universal testing machine (Kyoto, Japan) with a $500 \mathrm{~N}$ load cell. Testing was performed at a cross-head speed of $10 \% \mathrm{~min}^{-1}$, with the strain being measured using a video extensometer (high-speed camera, HPV-X2). The gauge length was set to $20 \mathrm{~mm}$ for each measurement. Seven specimens were analyzed for each network batch. The tensile strength was reported as the maximum strength at break. Young's modulus was calculated through the slope of the linear $\left(R^{2}=0.95-0.99\right)$ portion in the elastic region (around $0.1-0.5 \%$ strain).

\section{Cellulose, porosity, and moisture analysis}

Cellulose content of the final networks was estimated through soaking in $17.5 \mathrm{NaOH}$ according to (TAPPI 1999a) where the dissolved fraction was estimated as hemicellulose (and partly degraded low molecular weight cellulose). Porosity (P) of the networks was estimated using Equation (5) where $\rho_{s}$ and $\rho_{c}$ is the density of the sample and theoretical density of cellulose $\left(1.5 \mathrm{~g} \cdot \mathrm{cm}^{-3}\right)$, respectively. Moisture content of the networks prior to mechanical testing was estimated as the difference in weight before and after $24 \mathrm{~h}$ oven-drying at $105^{\circ} \mathrm{C}$.

$$
\mathrm{P}=1-\frac{\rho_{\mathrm{S}}}{\rho_{\mathrm{C}}}
$$

5

\section{Degree of polymerization}

Degree of polymerization (DP) of the final CNFs (through networks) was estimated through calculation of intrinsic viscosity after dissolution of the dry networks in $0.5 \mathrm{M}$ Copper (II)-ethylenediamine complex and measurement using an ISO 17025 certified Ubbelohde viscometer. The viscosity at infinite dilution (limiting viscosity, [ๆ]) was estimated according to (TAPPI 1999b) and used to estimate DP according to Equation (6) where $\mathrm{H}$ and $\mathrm{C}$ is the mass fraction of hemicellulose and cellulose, respectively. An assumption of a DP of 140 for the hemicellulosic fraction was furthermore made. Triplicate experiments were performed for each sample.

$$
\mathrm{DP}=\left(\frac{1.65 \cdot[\eta]-116 \mathrm{H}}{\mathrm{C}}\right)^{1.11}
$$




\section{Results}

\section{CNF properties}

The viscosity of the different CNF suspensions obtained after homogenization was evaluated between $0.12-0.30$ wt \% and shown in Fig. 1. The viscosity did not differ between suspensions up to approximately $0.18 \mathrm{wt} \%$ (see Fig. 1d). At the higher concentrations, the viscosity of WT (Fig. 1a) suspensions was higher compared to T1 (Fig. 1b) and T2 (Fig. 1C). At $0.30 \mathrm{wt} \%$ the viscosity plateaued at 52, 37 and $33 \mathrm{mPas}$ for $\mathrm{WT}, \mathrm{T} 1$ and T2, respectively. The presented viscosity trends indicate differences between CNFs from WT compared to T1 and T2. Factors that can influence viscosity include aspect ratio of CNFs (Iwamoto et al., 2014), volume fraction of fine CNFs (Lasseuguette et al., 2008), ionic strength and pH (Arcari et al., 2020; Moberg et al., 2017).

To identify the origin of the higher viscosity in WT the nanofibril yield, carboxylate content, suspension conductivity and surface area were assessed. A higher suspension carboxylate content was detected for WT (Table 2). The process yield from the initial wood mass showed no significant differences between the samples. The percentage of the yield that corresponded to fine nanofibrils (as determined using centrifugation) was similar for all samples at approximately $50 \mathrm{wt} \%$. However, statistical analysis indicates a small difference for WT compared to T1 and T2 (Table 2). Suspension conductivity was indistinguishable for all samples at around $40 \mu \mathrm{S} / \mathrm{cm}$. Surface area as estimated using Congo red, which binds to beta-glucan surface, was higher for WT compared to T1 and T2 with a difference in surface area of approximately $20 \mathrm{~m}^{2} \cdot \mathrm{g}^{-1}$. This data suggest that the increased viscosity of WT observed in Fig. 1 originates from a difference in aspect ratio of the CNFs which manifests as a more rapid increase in WT sample viscosity with increasing concentration due to a lower percolation threshold. The transition into a more viscous state at lower concentrations has been demonstrated when comparing relatively short cellulose nanocrystals compared to CNFs similar to the ones isolated in this study (Moberg et al., 2017). 
Table 2

Fibrillation metrics for CNFs isolated from WT, T1 and T2 with process yield, nanofibril yield, carboxylate content, viscosity $(0.30 \mathrm{wt} \%)$, suspension conductivity $(0,30 \mathrm{wt} \%)$ and surface area estimate of CNFs in suspension. Values in brackets indicate standard deviations. Mean values that do not share letters are significantly different according to Tukey's test $(p<0.05)$.

\begin{tabular}{|c|c|c|c|c|c|c|}
\hline $\begin{array}{l}\text { Tree } \\
\text { ID }\end{array}$ & $\begin{array}{l}\text { Process } \\
\text { yield } \\
\text { (wt \%) }\end{array}$ & $\begin{array}{l}\text { Nanofibril } \\
\text { yield } \\
\text { (\%) }\end{array}$ & $\begin{array}{l}\text { Carboxylate content } \\
(\mathrm{mmol} / \mathrm{g})\end{array}$ & $\begin{array}{l}\text { Viscosity } \\
\text { (mPa.s) }\end{array}$ & $\begin{array}{l}\text { Suspension } \\
\text { conductivity } \\
\text { (mS/cm) }\end{array}$ & $\begin{array}{l}\text { Surface } \\
\text { area } \\
\left(\mathrm{m}^{2} \cdot \mathrm{g}^{-1}\right)\end{array}$ \\
\hline WT & $\begin{array}{l}45.2 \\
(1.3)^{\mathrm{a}}\end{array}$ & $\begin{array}{l}50.8 \\
(0.3)^{\mathrm{a}}\end{array}$ & $0.69(0.10)^{a}$ & 51.8 & $37(5)^{a}$ & 100 \\
\hline $\mathrm{T} 1$ & $\begin{array}{l}44 \\
(2.0)^{\mathrm{a}}\end{array}$ & $\begin{array}{l}49.1 \\
(1.0)^{\mathrm{b}}\end{array}$ & $0.55(0.08)^{b}$ & 36.7 & $41(8)^{a}$ & 83 \\
\hline T2 & $\begin{array}{l}43.9 \\
(2.1)^{\mathrm{a}}\end{array}$ & $\begin{array}{l}48.2 \\
(0.8)^{b}\end{array}$ & $0.50(0.06)^{b}$ & 33.3 & $42(10)^{a}$ & 79 \\
\hline
\end{tabular}

The nanofibril yield indicates only a slight increase for WT compared to T1 and T2. It is thus likely that the fraction being discarded during fine nanofibril yield calculation contributes to the increased fibrillation metrics since the small difference in estimated CNF yield is unlikely on its own to give rise to the more distinct viscosity and surface area differences. Factors such as suspension concentration and centrifugation parameters affect the estimated fraction of nanofibrils. It has also been shown that there is a level of experimental variation regarding the fine CNF yield for TEMPO-oxidized CNFs as a function of carboxylate content (Isogai et al., 2011). Based on the carboxylate content observed in this study it is apparent that the chemical treatment has resulted in more oxidation of the retained solids for WT. This is interesting since there were no differences in the chemical composition and thus supports the hypothesis that the CMFs of T1 and T2 are less susceptible to fibrillation following mild TEMPO-oxidation. The conductivity of corresponding CNF suspensions was similar across all samples indicating no differences in ionic strength of the suspensions and, therefore, that appropriate filtration/purification was performed after TEMPO-oxidation. The surface area was approximately $20 \%$ higher for WT compared to T1 and T2 which aligns with the observed higher carboxylate content in WT. In accordance with previous reports this is indicative of a greater accessibility of the cellulosic surfaces that gradually becomes higher with increasing degree of fibrillation (Nge et al., 2013; Spence et al., 2011). Similar accessibility differences have been reported from increasing oxidation where structural changes inside the nanofibril aggregate occur as chemical oxidation proceeds (Sjöstedt et al., 2015). The CNF surface area estimated through adsorption of dyes in this study is comparable to those reported in previous studies ranging from 42-100 $\mathrm{m}^{2} \cdot \mathrm{g}^{-1}$ and $160-200 \mathrm{~m}^{2} \cdot \mathrm{g}^{-1}$ (Ferrer et al., 2012; Spence et al., 2010; 2011).

To further elucidate the CNF characteristics, AFM analysis was performed. The height of the nanofibrils comprising the suspensions is shown in Fig. 2 and revealed an average CNF diameter in the range of 0.5 $3.5 \mathrm{~nm}$ with no clear consistent differences between WT and T1/T2 regarding both presence of larger aggregates or differences in height of the smallest observed CNFs. 
From the size distribution (Fig. 2c) height ranges between $<1 \mathrm{~nm}$ to around $3 \mathrm{~nm}$ which is indicative that surface peeling or splitting of the native elementary CMFs I $(\approx 3 \mathrm{~nm})$ is taking place (Li and Renneckar, 2009; Usov et al., 2015). This can be explained by a disconnect between degree of fibrillation and fibril height (on single nanometer levels) (Lindström, 2017), which makes the observed CNF diameter more complicated than just being a generic fibrillation metrics. An example of this effect is the observation of a lower CNF diameter for samples which had an overall reduced degree of fibrillation (Jonasson et al., 2021). Another interesting aspect that can be observed from the micrographs is the indication of shorter fibril fragments from the transgenic lines. This is exemplified in Fig. 2 ( $a$ and $b$ ) for CNF from T1 where individual submicron fibrils are apparent to a larger extent compared to WT where the CNFs appear more seamless and interconnected. This could be a manifestation from variation in DP of the cellulose that comprises these fibrils, where DP is inherently correlated to nanofibril length (Shinoda et al., 2012). This would explain the difference in viscosity despite the relatively similar nanofibril yield, ionic strength, $\mathrm{pH}$ and volume fraction. This is further elaborated upon in the next section when analyzing corresponding CNF networks where network behavior is significantly influenced by DP of the CNFs that comprise them and subsequently a good tool for assessing variation (Henriksson et al., 2008).

\section{CNF network characterization}

The manufactured networks were tested for their capacity to bind water prior to hot pressing into dry networks. Water uptake is shown in Fig. 3 together with the visual appearance before and after swelling to max capacity. Networks made from the CNF suspensions could absorb $900-1100 \%$ of their initial weight with a slightly higher capacity for WT compared to T2. The capacity of T1 was indistinguishable from both WT and T2 where values were within the error margins of T2 and WT. A higher capacity for WT is supported both by the slightly higher degree of carboxylation of the solids in the WT-CNF suspensions and their corresponding increased surface area (Table 2).

CNFs with gradually increased degree of carboxylation have a higher affinity for swelling in water (PatiñoMasó et al., 2019). The increased water uptake combined with an overall higher surface area is indicative that the increased cellulose accessibility in WT-CNF suspensions persists throughout network formation after filtration and drying of the samples. This is attributed to a minimized degree of hornification during network manufacturing. This is mediated by the absence of hot-pressing when evaluating these wet networks, which does not irreversibly reduce water-uptake upon drying as much as more aggressive drying methods, e.g., oven-drying or hot-pressing.

The tensile strength, elongation-at-break and Young's modulus of the final dense and homogenous hotpressed networks is shown in Fig. $4 a$ and $b$ shows a higher tensile strength and elongation-at-break for WT compared to T2 and T1. Interestingly, Young's modulus (Fig. 4c) showed the opposite behavior with a lower Young's modulus for WT compared to T1/T2.

The increased tensile strength and elongation-at-break for WT relative T1 and T2 is supported by the data where WT-CNF showed higher nanofibril yield, viscosity, degree of oxidation and surface area (Table 2). All being factors which are relatable to greater network performance (Meng and Wang, 2019). The 
increased modulus for T1/T2 compared to WT indicates an opposite trend and supports the interpretation of shorter nanofibrils in T1 and T2. Shortening of nanofibrils have been reported to increase the stiffness of corresponding networks (Henriksson et al., 2008). An extreme case of this effect has been observed when comparing stiffness of networks made from CNF suspensions obtained from harsh (TEMPO/NaBr/ $\mathrm{NaClO}$ ) and mild (TEMPO/ $\mathrm{NaClO} / \mathrm{NaClO}_{2}$ ) oxidation of wood powder, where the harsh treatment resulted in a network modulus that was approximately $30 \%$ higher compared to the one from the mild treatment (Jonasson et al. 2020a). Furthermore, the DP was reduced already in the initial transgenic wood cellulose as determined by using size-exclusion chromatography (Bünder et al., 2020). It is thus possible that the decreased native cellulose DP for the transgenic lines is preserved throughout processing and manifested in the final networks as decreased strain-to-break and increased stiffness for corresponding networks.

To further elucidate the potential influence of DP on the mechanical behavior of the networks the $\mathrm{DP}_{\mathrm{V}}$ was estimated after dissolution in Cuen - a system that is compatible with TEMPO-oxidized CNFs (Isogai et al., 2011). The results are presented in Table 4 together with moisture content, porosity and a-cellulose content. The results indicate differences between WT and T1/T2 where WT CNFs have a higher DP compared to T1 and T2 both prior to and after nanofibrillation. The moisture content, porosity and cellulose content of the network were all relatively similar and are therefore likely not contributing to the difference in mechanical behavior.

Table 4

Physical properties of the networks as determined prior to mechanical testing. Properties include average number degree of polymerization (DPn) for the initial wood cellulose, average viscosity degree of polymerization of final networks, moisture content, network porosity and cellulose content. Mean values that do not share letters are significantly different according to Tukey's test $(p<0.05)$.

\begin{tabular}{|llllll|}
\hline Tree ID & Initial cellulose $\mathrm{DP}_{\mathbf{n}}$ & $\begin{array}{l}\text { CNF } \\
\mathrm{DP}_{\mathbf{v}}\end{array}$ & Moisture content (\%) & $\begin{array}{l}\text { Porosity } \\
(\%)\end{array}$ & a-cellulose (\%) \\
\hline WT & $1802(214)^{\mathrm{a}}$ & $1185(64)^{\mathrm{a}}$ & $10.3(2.1)^{\mathrm{a}}$ & $22(2)^{\mathrm{a}}$ & 80 \\
\hline T1 & $1644(137)^{\mathrm{b}}$ & $995(62)^{\mathrm{b}}$ & $11.3(2.8)^{\mathrm{a}}$ & $21(1)^{\mathrm{a}}$ & 82 \\
\hline T2 & $1637(129)^{\mathrm{b}}$ & $1061(37)^{\mathrm{b}}$ & $9.7(1.9)^{\mathrm{a}}$ & $23(2)^{\mathrm{a}}$ & 80 \\
\hline
\end{tabular}

The values that were obtained for $\mathrm{DP}_{\mathrm{V}}$ agree with early work on wood cellulose after being treated with the TEMPO/ $\mathrm{NaClO} / \mathrm{NaClO}_{2}$-system (Saito et al., 2009). The treatment also leads to large retention of initial DP, especially in comparison with the more rapid and aggressive TEMPO/ $\mathrm{NaBr} / \mathrm{NaClO}$-system (Isogai et al., 2018) where DP often approaches the level-of degree of polymerization (Shinoda et al., 2012). The difference in DP of the feedstock is likely the strongest effect that is detectable between the networks made from WT and T1/T2 where the mechanical properties in this study are supported by literature (Fukuzumi et al., 2013; Henriksson et al., 2008; Meng et al., 2017), where a more brittle and stiff behavior is expected from a network made from CNFs composed of cellulose with lower DP. 


\section{Conclusion}

Wood from transgenic trees with reduced expression of $C S / 1$ was subjected to nanofibrillation using direct TEMPO-oxidation ( $\mathrm{pH}=6.8)$ followed by high-pressure homogenization. The CNF suspensions and their corresponding networks were studied and compared with the CNFs from the wild type (control tree). CNF suspensions derived from transgenic trees showed lower degree of carboxylation, similar process yield, slightly decreased nanofibril yield and surface area. Viscosity increased more rapidly as a function of concentration for the wild type indicating a difference in aspect ratio and capacity for network formation. This was further detected in manufactured networks where the transgenic trees resulted in networks with reduced tensile strength, elongation-at-break and degree of polymerization, but with increased stiffness. Consequently, it was shown that the isolated CNFs were influenced by the reduced expression of CS/1 in developing wood and the augmented wood properties of the transgenics. This study thus shows that it is possible to influence the CNF quality by altering the wood properties of the feedstock and that native cellulose structure influences the final isolated CNF properties.

\section{Declarations}

Acknowledgements We are grateful for the financial support provided by FORMAS, Nano-wood project [942-2016-10]; Bio4Energy - Swedish strategic research program; Swedish Foundation for Strategic Research, HEALiX project [RMX18-0039]; and Kempe-stiftelserna. Open access funding provided by Luleå University of Technology

Declaration Authors declare that they have no conflict of interest

Author Contributions Conceptualization, S.J., L.B., A.B., T.N. and K.O.; methodology, S.J., A.B.; validation, S.J., L.B. and K.O.; formal analysis, S.J.; investigation, S.J.; resources, K.O., T.N.; data curation, S.J., A.B. and T.N.; writing-original draft preparation, S.J.; writing-review and editing, S.J., K.O., L.B., A.B. and T.N.; visualization, S.J.; supervision, K.O., L.B. T.N.; project administration, T.N. and K.O.; funding acquisition, T.N. and K.O. All authors have read and agreed to the published version of the manuscript.

\section{References}

1. Arcari M, Axelrod R, Adamcik J, Handschin S, Sánchez-Ferrer A, Mezzenga R, Nyström G (2020) Structure-property relationships of cellulose nanofibril hydro-and aerogels and their building blocks. Nanoscale 12:11638-11646. https://doi.org/10.1039/D0NR01362E

2. Bringmann M, Li E, Sampathkumar A, Kocabek T, Hauser M-T, Persson S (2012) POMPOM2/cellulose synthase interacting1 is essential for the functional association of cellulose synthase and microtubules in Arabidopsis. Plant Cell 24:163-177. https://doi.org/10.1105/tpc.111.093575

3. Bünder A, Sundman O, Mahboubi A, Persson S, Mansfield SD, Rüggeberg M, Niittylä T (2020) CELLULOSE SYNTHASE INTERACTING 1 is required for wood mechanics and leaf morphology in 
aspen. Plant J 103:1858-1868. https://doi.org/10.1111/tpj.14873

4. Fernandes AN, Thomas LH, Altaner CM, Callow P, Forsyth VT, Apperley DC, Kennedy CJ, Jarvis MC (2011) Nanostructure of cellulose microfibrils in spruce wood. Proceedings of the National Academy of Sciences 108, E1195-E1203. https://doi.org/10.1073/pnas.1108942108

5. Ferrer A, Filpponen I, Rodríguez A, Laine J, Rojas OJ (2012) Valorization of residual Empty Palm Fruit Bunch Fibers (EPFBF) by microfluidization: production of nanofibrillated cellulose and EPFBF nanopaper. Bioresour Technol 125:249-255. https://doi.org/10.1016/j.biortech.2012.08.108

6. Fukuzumi H, Saito T, Iwata T, Kumamoto Y, Isogai A (2009) Transparent and high gas barrier films of cellulose nanofibers prepared by TEMPO-mediated oxidation. Biomacromolecules 10:162165 https://doi.org/10.1021/bm801065u

7. Fukuzumi H, Saito T, Isogai A (2013) Influence of TEMPO-oxidized cellulose nanofibril length on film properties. Carbohydr Polym 93:172-177. https://doi.org/10.1016/j.carbpol.2012.04.069

8. Gibson E (1992) Wood: a natural fibre reinforced composite. Met Mater 8:333-336

9. Groover AT, Nieminen K, Helariutta Y, Mansfield SD (2010) Wood formation in Populus. Genetics and genomics of Populus. Springer, pp 201-224

10. Gu Y, Kaplinsky N, Bringmann M, Cobb A, Carroll A, Sampathkumar A, Baskin TI, Persson S, Somerville CR (2010) Identification of a cellulose synthase-associated protein required for cellulose biosynthesis. Proceedings of the National Academy of Sciences 107, 12866-12871. https://doi.org/10.1073/pnas.1007092107

11. Henriksson M, Berglund LA, Isaksson P, Lindstrom T, Nishino T (2008) Cellulose nanopaper structures of high toughness. Biomacromolecules 9:1579-1585. https://doi.org/10.1021/bm800038n

12. Isogai A, Saito T, Fukuzumi H (2011) TEMPO-oxidized cellulose nanofibers. nanoscale 3, 7185 https://doi.org/10.1016/j.progpolymsci.2018.07.007

13. Isogai A, Hänninen T, Fujisawa S, Saito T (2018) Catalytic oxidation of cellulose with nitroxyl radicals under aqueous conditions. Prog Polym Sci 86:122-148.

https://doi.org/10.1016/j.progpolymsci.2018.07.007

14. Iwamoto S, Kai W, Isogai A, Iwata T (2009) Elastic modulus of single cellulose microfibrils from tunicate measured by atomic force microscopy. Biomacromolecules 10:25712576 https://doi.org/10.1021/bm900520n

15. Iwamoto S, Lee S-H, Endo T (2014) Relationship between aspect ratio and suspension viscosity of wood cellulose nanofibers. Polym J 46:73-76. https://doi.org/10.1038/pj.2013.64

16. Jonasson S, Bünder A, Niittylä T, Oksman K (2020) Isolation and characterization of cellulose nanofibers from aspen wood using derivatizing and non-derivatizing pretreatments. Cellulose 27:185-203. https://doi.org/10.1007/s10570-019-02754-w

17. Jonasson S, Bünder A, Das O, Niittylä T, Oksman K (2021) Comparison of tension wood and normal wood for oxidative nanofibrillation and network characteristics. Cellulose 28:10851104 https://doi.org/10.1007/s10570-020-03556-1 
18. Kaffashsaie E, Yousefi H, Nishino T, Matsumoto T, Mashkour M, Madhoushi M, Kawaguchi H (2021) Direct conversion of raw wood to TEMPO-oxidized cellulose nanofibers. Carbohydr Polym 262:117938. https://doi.org/10.1016/j.carbpol.2021.117938

19. Knox JP (2008) Revealing the structural and functional diversity of plant cell walls. Curr Opin Plant Biol 11:308-313. https://doi.org/10.1016/j.pbi.2008.03.001

20. Lasseuguette E, Roux D, Nishiyama Y (2008) Rheological properties of microfibrillar suspension of TEMPO-oxidized pulp. Cellulose 15:425-433. https://doi.org/10.1007/s10570-007-9184-2

21. Li S, Lei L, Somerville CR, Gu Y (2012) Cellulose synthase interactive protein 1 (CSI1) links microtubules and cellulose synthase complexes. Proceedings of the National Academy of Sciences 109, 185-190. https://doi.org/10.1073/pnas.1118560109

22. Li Q, Renneckar S (2009) Molecularly thin nanoparticles from cellulose: isolation of sub-microfibrillar structures. Cellulose 16:1025-1032. https://doi.org/10.1007/s10570-009-9329-6

23. Lindström T (2017) Aspects on nanofibrillated cellulose (NFC) processing, rheology and NFC-film properties. Curr Opin Colloid Interface Sci 29:68-75. https://doi.org/10.1016/j.cocis.2017.02.005

24. Ma P, Fu S, Zhai H, Law K, Daneault C (2012) Influence of TEMPO-mediated oxidation on the lignin of thermomechanical pulp. Bioresour Technol 118:607-610.

https://doi.org/10.1016/j.biortech.2012.05.037

25. Meng Q, Li B, Li T, Feng X-Q (2017) A multiscale crack-bridging model of cellulose nanopaper. J Mech Phys Solids 103:22-39. https://doi.org/10.1016/j.jmps.2017.03.004

26. Meng Q, Wang TJ (2019) Mechanics of strong and tough cellulose nanopaper. applied mechanics reviews 71. https://doi.org/10.1115/1.4044018

27. Moberg T, Sahlin K, Yao K, Geng S, Westman G, Zhou Q, Oksman K, Rigdahl M (2017) Rheological properties of nanocellulose suspensions: effects of fibril/particle dimensions and surface characteristics. Cellulose 24:2499-2510. https://doi.org/10.1007/s10570-017-1283-0

28. Nge TT, Lee S-H, Endo T (2013) Preparation of nanoscale cellulose materials with different morphologies by mechanical treatments and their characterization. Cellulose 20:18411852 https://doi.org/10.1007/s10570-013-9962-y

29. Paredez AR, Somerville CR, Ehrhardt DW (2006) Visualization of cellulose synthase demonstrates functional association with microtubules. Science 312:1491-1495. https://doi.org/10.1126/science.1126551

30. Patiño-Masó J, Serra-Parareda F, Tarrés Q, Mutjé P, Espinach FX, Delgado-Aguilar M (2019) TEMPOoxidized cellulose nanofibers: a potential bio-based superabsorbent for diaper production. Nanomaterials 9:1271. https://doi.org/10.3390/nano9091271

31. Polko JK, Kieber JJ (2019) The regulation of cellulose biosynthesis in plants. Plant Cell 31:282-296. https://doi.org/10.1105/tpc. 18.00760

32. Puangsin B, Soeta H, Saito T, Isogai A (2017) Characterization of cellulose nanofibrils prepared by direct TEMPO-mediated oxidation of hemp bast. Cellulose 24:3767-3775. https://doi.org/10.1007/s10570-017-1390-y 
33. Saito T, Isogai A (2004) TEMPO-mediated oxidation of native cellulose. The effect of oxidation conditions on chemical and crystal structures of the water-insoluble fractions. Biomacromolecules 5 , 1983-1989.https://doi.org/10.1021/bm0497769

34. Saito T, Hirota M, Tamura N, Kimura S, Fukuzumi H, Heux L, Isogai A (2009) Individualization of nano-sized plant cellulose fibrils by direct surface carboxylation using TEMPO catalyst under neutral conditions. Biomacromolecules 10:1992-1996. https://doi.org/10.1021/bm900414t

35. Saxena IM, Brown Jr RM (2005) Cellulose biosynthesis: current views and evolving concepts. Ann Botany 96:9-21. https://doi.org/10.1093/aob/mci155

36. Schneider R, Tang L, Lampugnani ER, Barkwill S, Lathe R, Zhang Y, McFarlane HE, Pesquet E, Niittyla T, Mansfield SD (2017) Two complementary mechanisms underpin cell wall patterning during xylem vessel development. Plant Cell 29:2433-2449. https://doi.org/10.1105/tpc.17.00309

37. Shinoda R, Saito T, Okita Y, Isogai A (2012) Relationship between length and degree of polymerization of TEMPO-oxidized cellulose nanofibrils. Biomacromolecules 13:842-849. https://doi.org/10.1021/bm2017542

38. Sjöstedt A, Wohlert J, Larsson PT, Wågberg L (2015) Structural changes during swelling of highly charged cellulose fibres. Cellulose 22:2943-2953. https://doi.org/10.1007/s10570-015-0701-4

39. Spence KL, Venditti RA, Rojas OJ, Habibi Y, Pawlak JJ (2010) The effect of chemical composition on microfibrillar cellulose films from wood pulps: water interactions and physical properties for packaging applications. Cellulose 17:835-848. https://doi.org/10.1007/s10570-010-9424-8

40. Spence KL, Venditti RA, Rojas OJ, Habibi Y, Pawlak JJ (2011) A comparative study of energy consumption and physical properties of microfibrillated cellulose produced by different processing methods. Cellulose 18:1097-1111. https://doi.org/10.1007/s10570-011-9533-z

41. TAPPI (1999a) Alpha-, beta- and gamma-cellulose in pulp. Test Methods T $203 \mathrm{~cm}-99$ Atlanta. Technical Association of the Pulp and Paper Industry

42. TAPPI (1999b) Viscosity of pulp (capillary viscometer method). TAPPI T230 om-99.

43. Usov I, Nyström G, Adamcik J, Handschin S, Schütz C, Fall A, Bergström L, Mezzenga R (2015) Understanding nanocellulose chirality and structure-properties relationship at the single fibril level. Nat Commun 6:1-11. https://doi.org/10.1038/ncomms8564

44. Varanasi S, He R, Batchelor W (2013) Estimation of cellulose nanofibre aspect ratio from measurements of fibre suspension gel point. Cellulose 20:1885-1896. https://doi.org/10.1007/s10570-013-9972-9

45. Wågberg L, Decher G, Norgren M, Lindström T, Ankerfors M, Axnäs K (2008) The build-up of polyelectrolyte multilayers of microfibrillated cellulose and cationic polyelectrolytes. Langmuir 24:784-795. https://doi.org/10.1021/la702481v

46. Wu X, Moon RJ, Martini A (2014) Tensile strength of I $\beta$ crystalline cellulose predicted by molecular dynamics simulation. Cellulose 21:2233-2245. https://doi.org/10.1007/s10570-014-0325-0

\section{Figures}



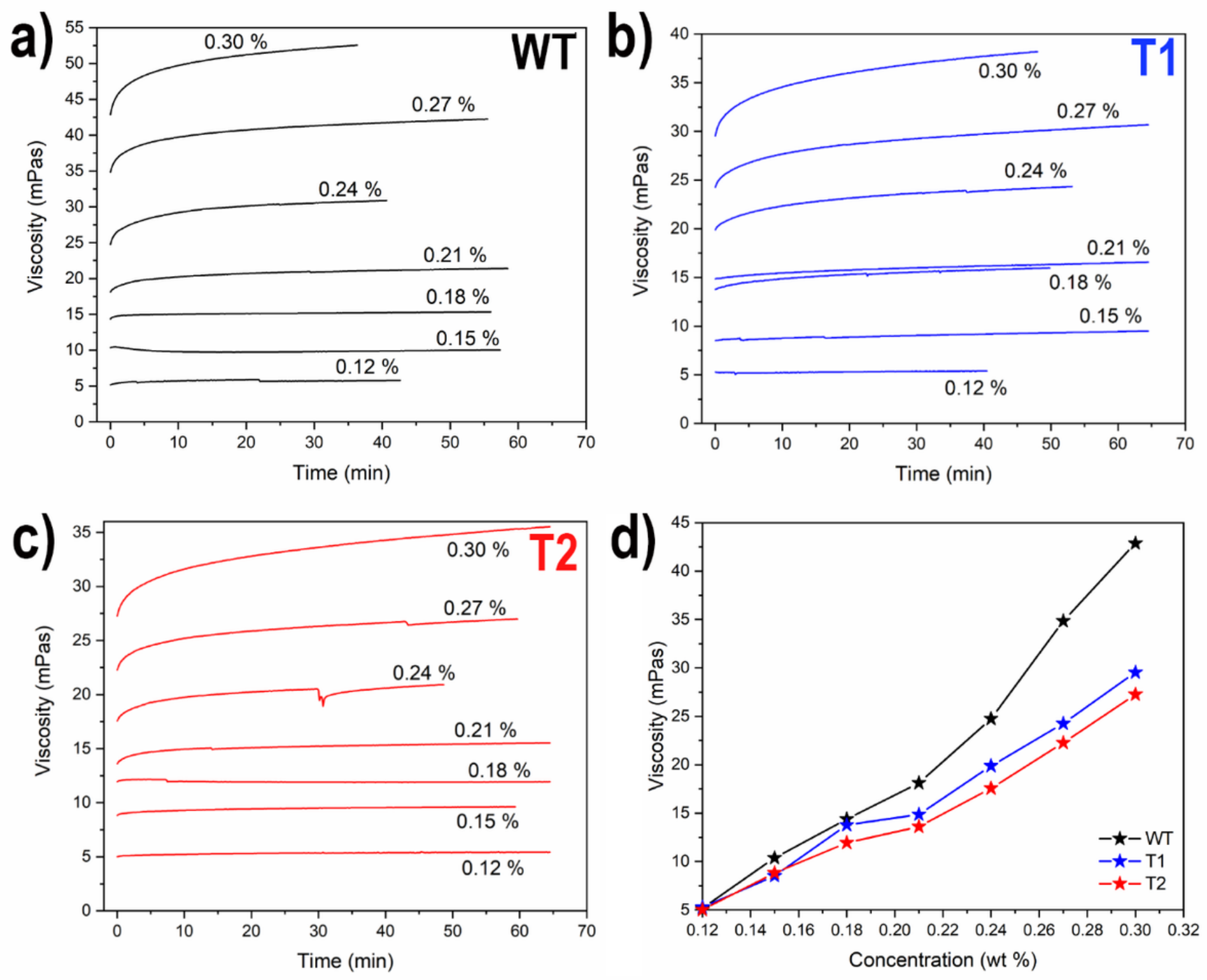

\section{Figure 1}

Viscosity as a function of time for different CNF suspensions obtained from a) WT, b) T1, c) T2 and d) Corresponding individual value of viscosity as a function of suspension concentration. 
a)
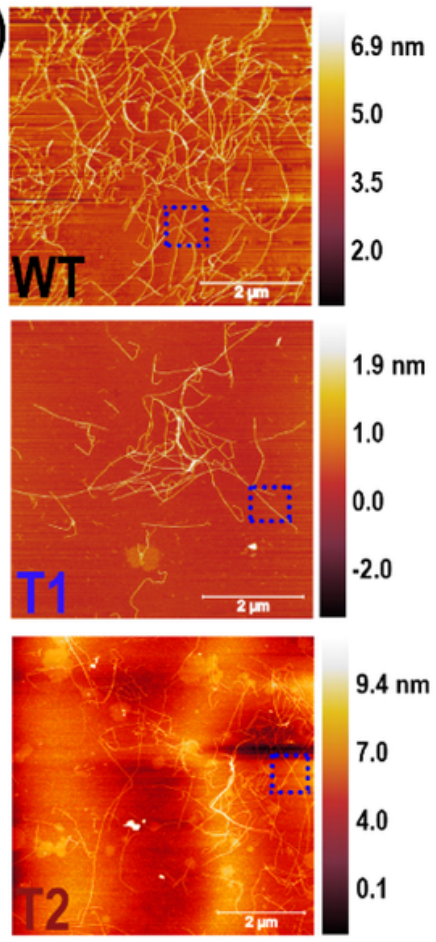

b)

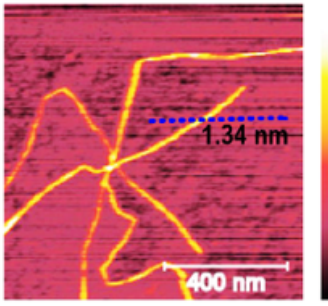

$2.5 \mathrm{~nm}$

c)

1.5

0.0

$-1.0$
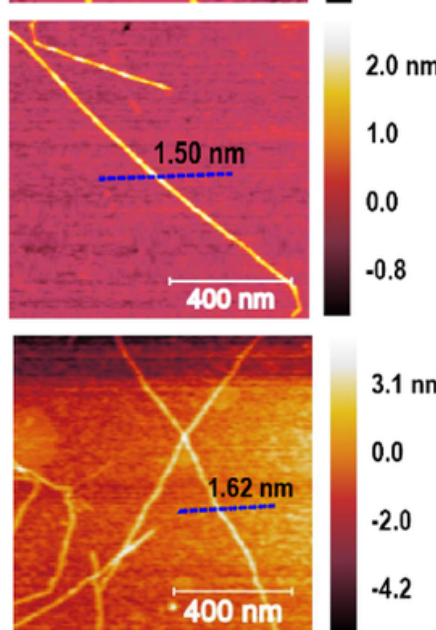

$-4.2$

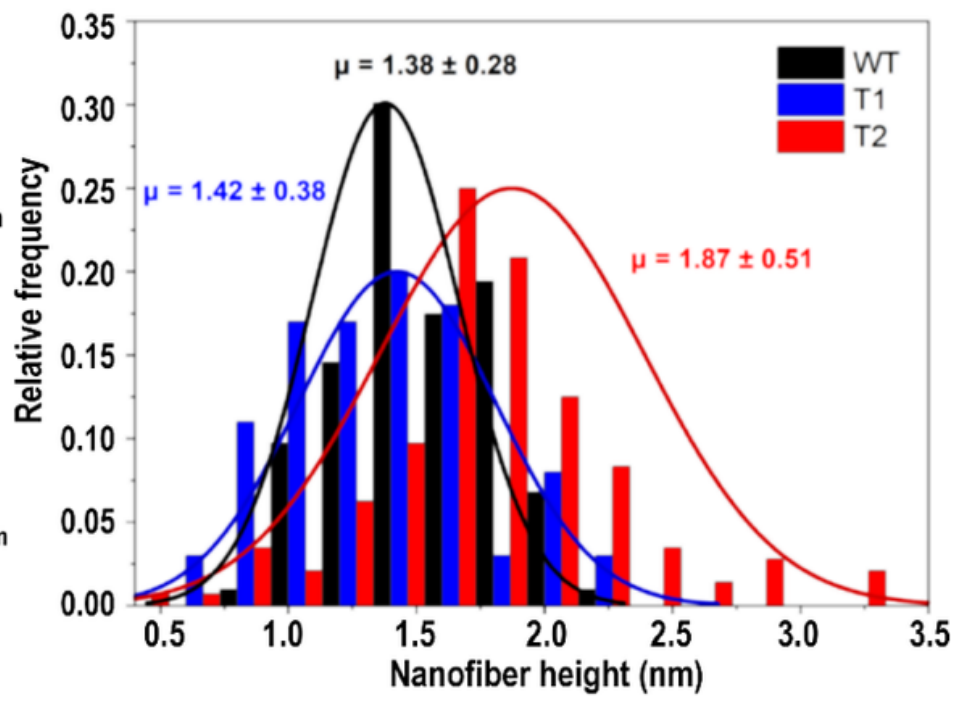

Figure 2

a) Atomic force micrographs of CNFs from WT, T1 and T: b) Close-up on representative individual nanofibrils and measured height; c) Size distribution of corresponding CNF diameter. Variation represent \pm SD $(n \geq 100)$.

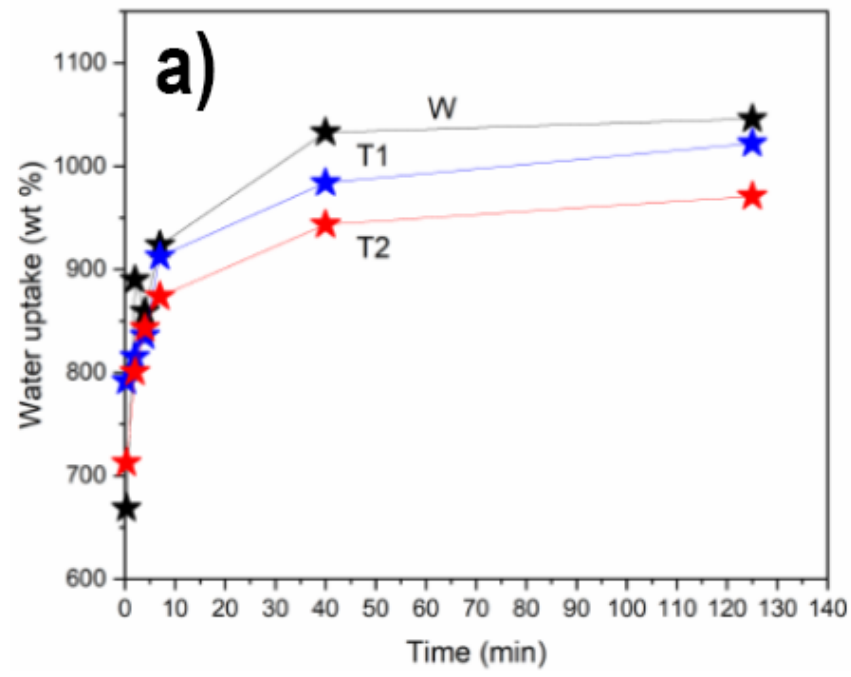

b)

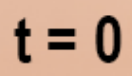

c)

$\mathrm{t}=120 \mathrm{~min}$

Figure 3

a) Water uptake as a function of time for hydrogel networks made from the CNF suspensions; b) Visual appearance of air-dried networks ( $>90 \%$ solid content); c) Rehydrated networks at max swelling ( $<8 \%$ solid content). 

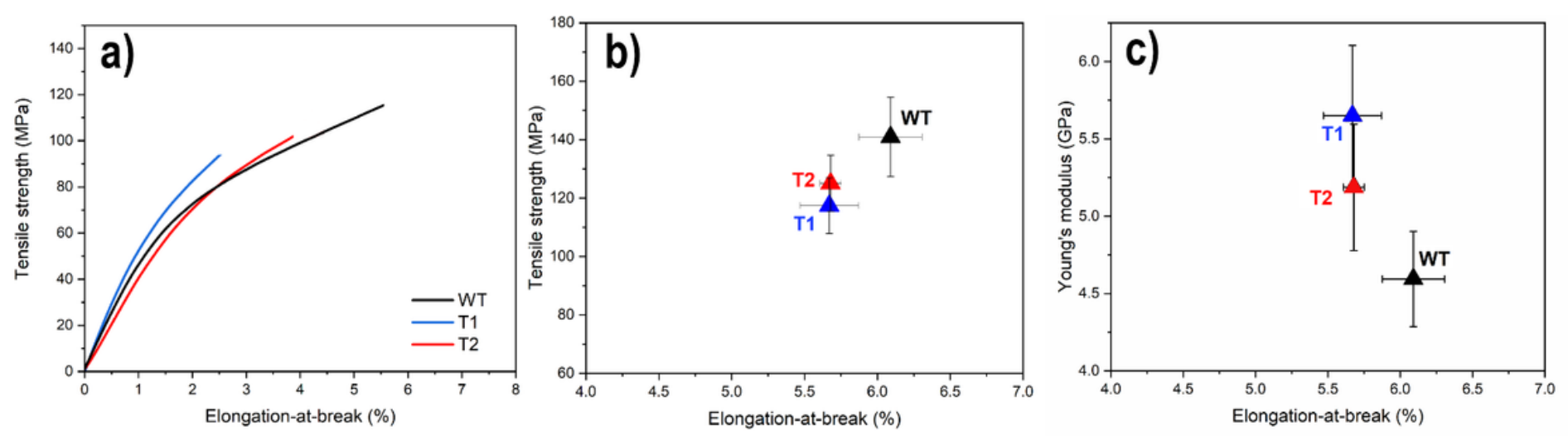

Figure 4

a) Mechanical properties of CNF networks with example stress vs. strain curves; $b$ ) Relation between tensile strength and elongation-at-break; c) Young's modulus vs. elongation-at-break. Error bars represent $\pm \mathrm{SD}(\mathrm{n}=7)$.

\section{Supplementary Files}

This is a list of supplementary files associated with this preprint. Click to download.

- GraphicAbstract.png 